\title{
Pesquisa em Serviço Social: concepções e críticas ${ }^{1}$
}

\author{
Carlos Antonio de Souza Moraes \\ Universidade Federal Fluminense (UFF)
}

\section{Pesquisa em Serviço Social: concepções e críticas}

Resumo: O artigo objetiva problematizar as concepções e os significados de pesquisa acadêmico-científica e pesquisa em serviços. Sua relevância é inerente ao fato de que a pesquisa para o Serviço Social brasileiro, na atualidade, é entendida como atribuição profissional que se expressa na formação e no trabalho. Metodologicamente recorreu-se a pesquisa bibliográfica realizada em livros, revistas acadêmicocientíficas, dissertações e teses na área de Serviço Social que abordam os seguintes eixos que também compõem o roteiro do estudo: pesquisa e produção de conhecimentos em Serviço Social; pesquisa e trabalho profissional. Os resultados apontam que o Serviço Social, enquanto área produtora de conhecimentos, insiste no questionamento e enfrentamento da cultura dominante, embora afetado pela realidade capitalista que dialeticamente o impulsiona em dados momentos a reduzir a pesquisa a sistematizações de levantamentos. Além disso, há necessidade de ampliar as discussões da pesquisa para graduação em Serviço Social como possibilidade de romper o academicismo e a unidisciplina.

Palavras-chave: Serviço Social. Pesquisa. Produção de conhecimentos. Pesquisa em serviços. Pesquisa associada ao trabalho profissional.

\section{Research in Social Work: Conceptions and criticisms}

Abstract: This article problematizes the concepts and meanings of academic-scientific research and research in services or associated to professional work. Its relevance is inherent to the fact that current research for Brazilian social work is understood as a professional attribution that is expressed in education and work. The methodology uses an exploratory study and works with bibliographic analysis based on locating, compiling and summarizing materials organized in the two lines of the study: research and production of knowledge in the field of social work; research and professional work. Results point to the reduction of academic research, activities of systematization and the need to expand discussions about research to undergraduate studies in social work to allow breaking the marks of academicism and "unidisciplinarity".

Keywords: Social Work. Research. Production of knowledge. Research in services. Research associated to professional work. 


\section{Introdução}

A concepção geral de pesquisa que orienta o debate do Serviço Social no tempo atual é resultado de um processo de críticas ao conservadorismo profissional, que estão presentes nos princípios da organização curricular da ABEPSS de 1996 e no perfil profissional delineado por tais diretrizes.

A análise desse documento indica que a produção de conhecimentos na formação e no trabalho profissional não apenas contribui para o debate teórico-metodológico do Serviço Social, mas é reconhecida como fenômeno político e estratégico-interventivo. Isso significa que os desdobramentos da produção de conhecimentos no Serviço Social não se dissociam dos valores profissionais relativos ao projeto de sociedade, articulados à sua materialização por meio da construção de intervenções individuais e coletivas qualificadas, que realimentam novas possibilidades de desvendar as contradições da sociedade capitalista do século XXI.

Diante disso, não é surpreendente a afirmação de que a pesquisa para o Serviço Social, na atualidade, é entendida como uma atribuição profissional que se expressa na formação e no trabalho do assistente social. Na formação profissional ela tem sido denominada pesquisa acadêmico-científica, que é realizada na graduação e tem a pós-graduação como espaço privilegiado, na tentativa de analisar a realidade social e, ao mesmo tempo, responder às exigências das instituições financiadoras que avaliam os projetos de pesquisa, e também aquelas (Coordenação de Aperfeiçoamento de Pessoal de Nível Superior - CAPES; e Ministério da Educação - MEC) que apreciam e recomendam os cursos de graduação e pós-graduação.

A partir da década de 1980 e, sobretudo, ao longo dos anos 1990, a pesquisa também tem sido compreendida como constitutiva do trabalho profissional, visto que assume papel importante para o posicionamento ético e estratégico na construção de ações profissionais críticas e qualificadas na prestação dos serviços à população. Ações que devem estar pautadas na análise dos processos sociais e dos desafios ciclicamente redesenhados na agenda das políticas sociais e do trabalho profissional.

A distinção existente entre pesquisa acadêmico-científica e pesquisa em serviços ou associada ao trabalho profissional é marcada por uma série de problematizações que se aproximam na compreensão e defesa de sua centralidade no trabalho docente e do assistente social caracterizado como de campo. Porém, se distanciam ao alimentar o debate do caráter do conhecimento produzido.

O reconhecimento da não isenção de conflitos no debate teórico-metodológico produzido pelo Serviço Social contemporâneo, a respeito da pesquisa e da produção de conhecimentos na área, não invalida a necessária compreensão proposta por esse artigo a respeito dos significados destas pesquisas (acadêmico-científica e em serviços ou associada ao trabalho profissional) para o Serviço Social na atualidade.

Ou seja, é fundamental a reflexão a respeito do que a academia tem discutido em termos de pesquisa para o Serviço Social, de forma ampliada e para o debate mais crítico em relação a qual desses tipos de pesquisas (ou se ambas ou até nenhuma delas) têm tido centralidade em nossa formação profissional, em termos teóricos e de construção das ações formativas voltadas aos discentes, embora a pesquisa (de forma ampliada) tenha sido assumida como pedra angular da formação profissional.

Diante disso, o artigo objetiva problematizar as concepções e os significados de pesquisa acadêmico-científica e pesquisa em serviços ou associada ao trabalho profissional. Metodologicamente, trata-se de pesquisa teórica de caráter bibliográfico. Para tanto, recorreu-se a livros clássicos da área de Serviço Social e que discutem o tema em questão, às revistas Serviço Social e Sociedade, Katálysis e Temporalis, disponíveis on-line, além do Banco de Dissertações e Teses da CAPES e dos Anais do Encontro Nacional de Pesquisadores em Serviço Social (ENPESS), com o objetivo de localizar, compilar e fichar os materiais pautados nos seguintes eixos: pesquisa e produção de conhecimentos em Serviço Social; pesquisa e trabalho profissional.

O material coletado na pesquisa bibliográfica foi lido, fichado e organizado. Sua leitura horizontal e exaustiva proporcionou a identificação de pontos de consenso, contradição e a coerência interna das informações, permitindo a apreensão das estruturas de relevância e ideias centrais (MINAYO, 2014).

Diante disso, e pautado nestes procedimentos metodológicos, a problematização construída neste artigo se divide em dois momentos: no primeiro, por meio do debate a respeito da pesquisa acadêmico-científica na área de Serviço Social no Brasil do tempo atual e, no segundo, através da análise da pesquisa em serviços.

\section{A pesquisa acadêmico-científica no serviço social brasileiro}

Os avanços da pesquisa no Serviço Social são resultados, sobretudo, das produções germinadas no espaço da pós-graduação stricto sensu, que são fundamentais para produção e reprodução da comunidade científica e técnica (KAMEYAMA, [1998?]). Também é importante destacar que, contrariamente à gradua- 
ção, a pós-graduação é construída majoritariamente em instituições públicas. Mas, na particularidade das privadas, seus cursos concentram-se nas Pontifícias Universidades Católicas (PUC-SP, PUC-RIO, PUCRS, PUC GOIÁS).

A Pós-Graduação em Serviço Social no Brasil vem consolidando-se e expandindo-se significativamente nas últimas duas décadas. Entre 2004 e 2014, a área ampliou de 18 para 33 Programas de Pós, havendo um crescimento de mais de 100\% se comparado com a década de 1990 (ZACARIAS et al., 2014). Esses Programas de Pós-graduação na área de Serviço Social concentram suas discussões na área de política social, seguida pela política pública e, ainda, existem outros temas em menor proporção, como: Serviço Social e Desenvolvimento Regional (UFF), Serviço Social e Política Social (UEL), Serviço Social, Trabalho e Questão Social (UECE) (ZACARIAS et al., 2014).

Entre as linhas de pesquisa, há ênfase no debate da questão social, evidenciando sua centralidade na produção da área, "seja como eixo de compreensão das próprias políticas sociais, como base sócio-histórica do Serviço Social e objeto de trabalho, bem como elemento central nas diretrizes curriculares da ABEPSS para a formação e exercício profissional” (ZACARIAS et al., 2014).

Entre os cursos de mestrado e doutorado que apresentam exigência de disciplinas obrigatórias, há predominância da temática "políticas sociais/políticas públicas”, embora também tenham destaque disciplinas que evidenciam particularidades do Serviço Social, vinculadas "ao trabalho, formação e ao arcabouço teóricometodológico e ético-político da profissão, bem como o direcionamento para a formação em pesquisa" (ZACARIAS et al., 2014).

Esse processo histórico, de conquista e abertura de novos espaços acadêmico-organizativos por parte da categoria é fundamental na disputa das ideias, solidificando o pluralismo, marcado por novas formas de pensar a realidade capitalista, a vida social, as relações sociais e as políticas sociais.

Nesse sentido, o Serviço Social ultrapassa a exclusiva e histórica condição de consumidor de conhecimentos produzidos pelas outras áreas das Ciências Sociais, superando tal subalternidade e construindo a formação de uma massa crítica, por meio de quadros intelectuais que, na disputa de ideias, na produção e no engajamento político, têm enfrentado a cultura dominante e o conservadorismo que insiste em permanecer no interior da profissão, ameaçando a dimensão intelectiva do trabalho profissional na perspectiva ético-política atual (MORAES, 2016a).

Para Simionatto (2014), a produção de conhecimentos pelo Serviço Social tem avançado em toda a América Latina, ampliando a interlocução com as Ciências Sociais em vários temas, com destaque para:

[...] os processos de globalização e mundialização do capital, as mudanças no mundo do trabalho e suas consequências para a classe trabalhadora, tanto do ponto de vista objetivo, com a flexibilização e a precarização do trabalho, o crescimento do desemprego, o aumento do exército industrial de reserva, bem como do ponto de vista subjetivo, mediante a cooptação da classe trabalhadora por meio de um intenso processo de transformismo (IASI, 2012, p. 286), especialmente em seus institutos de representação coletiva. No âmbito das relações Estado e sociedade, as produções captam e debatem as 'contrarreformas' e sua incidência no campo dos direitos sociais e das conquistas históricas das lutas dos trabalhadores. Temas como políticas sociais e suas interfaces com os direitos, a cidadania, a democracia, a sociedade civil, os movimentos sociais, a participação popular, aparecem em produções e pesquisas mediante análises críticas, desvendam a dinâmica do capitalismo contemporâneo e, ao mesmo tempo, oferecem subsídios à investigação de um vasto campo de expressões da questão social, tais como pobreza, violência, fome, desemprego, relações de gênero, carências materiais e existenciais, vinculadas às complexas determinações sociais das novas condições históricas. (SIMIONATTO, 2014, p. 17-18).

Sabe-se que todos esses processos são fruto das transformações gerais da sociedade, do Estado, das políticas sociais e das requisições colocadas ao Serviço Social, que ampliam seu mercado de trabalho e o faz refletir criticamente a respeito de seu lugar, atribuições e competências na sociedade capitalista. Os debates, construídos no interior do Serviço Social, são substanciais para sua análise, compreensão de sociedade e seus posicionamentos teórico-metodológico, ético-político e técnico-operativo, bem como sua relação com o mercado de trabalho. Esse conjunto de elementos vai redimensionar qualitativamente a compreensão e relação do Serviço Social com a pesquisa e a produção de conhecimentos que dialeticamente trarão novas possibilidades para o redimensionamento constante da profissão.

Também não se pode negar que esse salto na produção de conhecimentos do Serviço Social contemporâneo é marcado pelo uso das abordagens qualitativas, embora não deixem de ser importantes, para a profissão, os dados quantitativos. 
Além disso, Mauriel e Guedes (2013), ao analisar relatos de participantes do curso ABEPSS - Itinerante das Regionais Leste e Sul I, identificaram as dificuldades e os desafios mais significativos à pesquisa na formação profissional do assistente social.

Entre os depoimentos dos participantes, houve clareza em relação à abrangência da pesquisa em Serviço Social, como proposta pelas Diretrizes Curriculares de 1996, além da compreensão de sua natureza e procedimentos. Também compreendem que a articulação entre ensino, pesquisa e extensão são fundamentais para “[...] ultrapassar os muros da teorização, do pragmatismo, da ausência da relação entre teoria e prática" (MAURIEL; GUEDES, 2013, p. 18), ancorados na direção da consolidação do projeto profissional.

Assim, a pesquisa acadêmico-científica tem sido capaz de gerar teorias na área de Serviço Social que embora estejam sempre sujeitas a problematizações e reformulações - tem tentado, a partir de princípios e definições gerais, explicar uma gama ampla de fenômenos através de um esquema conceitual abrangente e, ao mesmo tempo, sintético. Historicamente construída, enquanto análise e expressão do interesse de classes, tem-se objetivado avançar na construção de reflexões vinculadas ao conhecido e desconhecido, por meio de aproximações e distanciamentos que intentam desvendar dimensões não pensadas ou refletidas superficialmente a respeito da realidade, que só se revelam a partir de interrogações elaboradas por meio do processo de construção teórica.

Dessa maneira, a nossa concepção de pesquisa acadêmico-científica na área de Serviço Social a compreende como a tentativa de explicar os fenômenos reais por meio de critérios científicos e de um esquema conceitual capaz de apreender sua estrutura, gênese, desenvolvimento, dinâmica e contradições na sociedade de classes.

Fatores esses que são fundamentais para organização lógica dos aspectos selecionados na realidade empírica e para análises pautadas na busca de sua superação. "O ato de conhecer e o conhecer em ato" (BARBIANI, 2004), presente na pesquisa em Serviço Social, tem objetivado, a partir do fenômeno externo, capturar a determinação histórica da realidade, além de sua simultaneidade, diversidade e complexidade, buscando fazer a difícil travessia do singular ao particular, determinado e mediado pelo universal, que imerge no movimento da realidade.

Como fenômeno político, hegemonicamente, a pesquisa acadêmico-científica no Serviço Social tem se expressado a serviço da produção da consciência humana, questionando os significados de liberdade na sociedade capitalista como contribuição para a transformação social por meio da defesa dos interesses da classe trabalhadora, da afirmação de seus direitos, da tentativa de combate a toda e qualquer forma de discriminação, da mobilização dos trabalhadores por meio do “despertar de suas consciências” (SIMIONATTO, 2014, p. 15), na tentativa de contribuição para construção de uma nova ordem social.

Compreendendo-se que a produção e o espraiamento do conhecimento/teoria estejam, sobretudo, vinculados à pesquisa acadêmica, nos dias atuais é possível identificar uma multiplicidade de instituições de ensino superior (públicas, privadas) em modalidades de ensino também heterogêneos (presencial, semipresencial e à distância) que não desenvolvem projetos de pesquisa e extensão na proporção necessária, seja pela precariedade, falta de investimento e sucateamento público, seja por se vincularem exclusivamente ao mercado, através de um ensino, e somente ensino, de qualidade que, muitas vezes, pode ser questionada.

Dessa forma, mesmo sendo o lugar primordial para problematização, reflexão, questionamento, debates, estudos e pesquisas e, portanto, para tentar avançar na produção de conhecimentos científicos, afirma-se que muitas instituições de ensino superior não têm cumprido, como deveriam, seu papel científico e social. Seja por não priorizarem a tríade ensino, pesquisa e extensão, seja por se precarizarem em demasia, proporcionando acesso aos discentes sem estrutura adequada e com número insuficiente de profissionais.

A este respeito, optou-se por recorrer a Setúbal (2011, p. 75):

[...] a forma como é produzida a universidade está intimamente relacionada à maneira pela qual as condições materiais, culturais e até espirituais do homem são produzidas, razão por que a universidade, em sua manifestação concreta, é a expressão ‘[...] do grau de desenvolvimento da sociedade em seu conjunto’ (SAVIANI, 1992, p. 99); manifesta os seus valores e estimula o desenvolvimento de produtos de acordo com as necessidades dessa mesma sociedade. Enfim, se a instituição universidade é produzida de acordo com o grau de desenvolvimento de uma dada sociedade, então, no caso do Brasil, ela se constrói dentro do projeto capitalista de produção da existência humana dessa sociedade. [...] Em outras palavras, podemos dizer que de 1980 para cá, as cores que pintam os quadros da universidade deste país são as mesmas que colorem a tecnocracia e a modernização acelerada, expressando essa última o desenvolvimento sob a égide do capitalismo. E no bojo dessa relação capital/sociedade e capital/sociedade e universidade que se encontram os programas de pós-graduação. Por isso eles não fogem às regras desse sistema nem quando privilegiam áreas de produção de conhecimento com as suas respectivas linhas nem quando se voltam para o seu objetivo maior, que é formar pesquisadores e fomentar a pesquisa. 
Por outro lado, se há esse tipo de formação profissional, possivelmente isso pode interferir na capacidade de abstração não apenas dos discentes, mas também dos docentes, que, geralmente, realizam grande esforço pessoal para cumprir suas atribuições. Portanto, mesmo estando em um lugar que, por essência, deveria ser de avanços para a categoria profissional, através, sobretudo, da articulação, com qualidade, entre ensino, pesquisa e extensão e, consequentemente, da produção de conhecimentos e (re)construção da teoria, identifica-se que não são todos os docentes que desenvolvem pesquisas. Menos ainda os que constroem e operacionalizam propostas de pesquisas que contribuirão efetivamente para produção e alargamento do conhecimento científico na área de Serviço Social e afins.

Ao capturar a centralidade do humano na construção do conhecimento científico na área de Serviço Social no século XXI, torna-se importante identificar quem são os profissionais comprometidos com a prática da construção de conhecimentos e que desenvolvem um esforço pessoal na tentativa de alimentar, de forma permanente, a docência/ensino, banhados pelo movimento da pesquisa.

As estratégias desenvolvidas por esses docentes, que estão, sobretudo, em universidades de pequeno porte (com forte ênfase no ensino e formação para o mercado de trabalho), são as mais variadas e envolvem a mobilização de recursos, que são até pessoais em alguns casos (BOURGUIGNON, 2008).

Essa situação foi identificada por Mauriel e Guedes (2013) durante o curso ABEPSS-Itinerante. Para as autoras, os docentes de unidades privadas de ensino superior, sobretudo, têm se empenhado na busca de qualificação, por meio de mestrados e doutorados, para construção de experiência de pesquisa em sua trajetória acadêmica, pois entendem tal importância para sua formação profissional e para atuação na docência.

Esses esforços são fundamentais para manter o fôle-

\section{Como fenômeno político,} hegemonicamente, a pesquisa acadêmico-científica no

$$
\text { Serviço Social tem se }
$$$$
\text { expressado a serviço da }
$$

produção da consciência

humana, questionando os

$$
\text { significados de liberdade na }
$$

sociedade capitalista como

contribuição para a

transformação social por meio

da defesa dos interesses da

classe trabalhadora [...] go crítico no interior das universidades. A função do intelectual é despertar consciências, impedir a alienação e a resignação ao discurso envolvente das elites, desafiar o silêncio e a naturalidade do poder invisível em todos os espaços. Sempre que possível esse é um caminho necessário na luta contra a indiferença, na criação e propagação do desassossego, no questionamento de conceitos, elucidando e opondo dialeticamente os conflitos (SIMIONATTO, 2014).

A construção do assistente social intelectual, produtor de conhecimentos críticos e politizadores da realidade social, tem sido permeada por desafios e fragilidades desenhadas pela realidade social capitalista, que produzem implicações diretas ao Serviço Social.

Para Mendes e Almeida (2014), os desafios e as fragilidades das recentes tendências da pesquisa em Serviço Social têm se avolumado com o número reduzido de pesquisadores vinculados às agências de fomento nacionais e internacionais, com implicações para as reduzidas demandas encaminhadas ao $\mathrm{CNPq}$, e as modestas demandas recomendadas, o que tem se materializado na insignificância orçamentária do Programa de Serviço Social se comparado ao de Psicologia, que integra o mesmo comitê de assessoramento junto ao CNPq.

Além disso, as autoras (MENDES; ALMEIDA, 2014) apontam fragilidades nos estudos com unidade investigativa restrita, tipificados, majoritariamente, como estudos de caso; dificuldades na elaboração de projetos de pesquisa com domínio teórico-metodológico, havendo predomínio do cariz interventivo; além de baixa circulação da produção de conhecimentos da área, preponderantemente limitados aos periódicos dos programas de pós-graduação, que têm sido referência ao próprio Serviço Social, muitas vezes, de forma endógena.

Além desses desafios, Vasconcelos et al. (2013), ao estudarem a produção de conhecimentos a partir dos anais do ENPESS (2008, 2010) e CBAS (2007, 2010), identificaram que os trabalhos analisados têm priorizado uma abordagem analítica em detrimento de uma discussão também propositiva, capaz de tecer reflexões que transformem o conhecimento em capacidade de atuação.

Essas situações, vinculadas à pesquisa acadêmico-científica, permitem a compreensão de que essa profissão, embora tenha avançado nos últimos 30 anos e se consolidado como área produtora de conhecimentos, tem enfrentado uma série de desafios vinculados predominantemente a dois vetores: teórico-metodológicos e ético-político/organizativos. 
Os desafios teórico-metodológicos relacionam-se à capacidade de análise e de proposição à apropriação da teoria crítica, aos caminhos metodológicos trilhados na construção do conhecimento e ao distanciamento crítico do objeto de estudo, tanto no debate-interno da categoria e da categoria profissional com as demais áreas do saber.

Os desafios éticos-políticos/organizativos se manifestam como desdobramentos de estratégias necessárias para maior participação do Serviço Social em órgãos de pesquisa nacional e internacionais; na articulação, debate e crítica ao produtivismo, inclusive pelos órgãos da categoria; na articulação do debate da pesquisa acadêmico-científica entre instituições e cursos de Serviço Social e outros cursos de maneira geral; na ampliação do debate teórico-metodológico e ético-político de forma interdisciplinar, dialogando com diferentes áreas do saber e construindo mecanismos de participação coletiva no debate acadêmico-científico.

Esses elementos indicam que os avanços na produção de conhecimentos devem pautar-se pela tentativa de construção de novas liberdades, capazes de fomentar o debate político-profissional e também instrumentalizar as intervenções dos assistentes sociais.

\section{Pesquisa em serviços ou associada ao trabalho profissional}

A necessária defesa da pesquisa em serviços não ignora diferenças existentes com a pesquisa acadêmica. Como sinalizado anteriormente, a pesquisa acadêmico-científica objetiva à elaboração de teses, dissertações, artigos, livros. Trabalha com critérios científicos pré-estabelecidos e tem por finalidade a (re)construção de conhecimentos científico/teoria, embora no Serviço Social também haja grande preocupação com a função social dos conhecimentos produzidos, contribuindo especialmente, para a (re)construção e avaliação de políticas sociais. Na academia e nos diversos espaços sócio-ocupacionais a pesquisa realizada pelo assistente social é construída através de um planejamento que, geralmente, tem por base as investigações desenvolvidas em seu trabalho profissional.

Na particularidade da pesquisa em serviços, essas investigações, inerentes à postura/atitude profissional, integram as habilidades técnicas e operativas do assistente social. Portanto, a aplicação dos instrumentos de trabalho não deve ser dissociada da dimensão investigativa e da sistematização do trabalho que, tendo um norte ético, político, teórico e metodológico, serão essenciais para (re)conhecer a realidade de trabalho e (re)criar estratégias interventivas mais críticas e qualificadas.

Se as instituições de ensino superior se apresentam como lugar primordial na tentativa de avanços na produção de conhecimentos científicos ${ }^{2}$, o mesmo não ocorre nos espaços sócio-ocupacionais dos assistentes sociais, que aspiram profissionais operativos, subservientes e capazes de construir um trato humanizador no contexto da falta de atendimentos qualificados às demandas e da precariedade de recursos humanos, materiais, físicos/estruturais e orçamentários destinados ao social.

Nessas situações, o domínio técnico do trabalho deve ser dissociado de reflexões críticas que dinamizem o poder institucional na direção da consolidação e ampliação de direitos dos usuários (perspectiva oposta à defendida pelo atual projeto profissional). Assim, a pesquisa, quando associada ao trabalho profissional, tem sido fruto de um movimento construído pelo Serviço Social/assistente social - geralmente associada a cursos de pós-graduação ou à supervisão de estagiários que desenvolvem pesquisas, como atividades vinculadas à graduação - e/ou uma exigência institucional para defesa de suas prioridades.

O movimento profissional deve ser pautado pela tentativa de, em conformidade com os valores éticopolíticos profissionais atuais, edificar saberes críticos e propositivos à realidade, tentando garantir à população a qualidade dos serviços prestados.

Mas, quando é fruto de exigência institucional, há que se ter cuidados redobrados na construção do trabalho de pesquisa, além da leitura e análise dos dados, garantindo o espaço da construção de conhecimentos como um espaço ético e capaz de, com competência crítica, articular o saber na construção de fazeres transformadores e compromissados com a classe subalterna.

Para associar a pesquisa ao trabalho profissional, o assistente social precisa investir em sua capacidade investigativa, por meio de postura e ação, articulando-as à construção do hábito de anotação sistemática do fazer profissional.

À medida que o assistente social parte do princípio de que a realidade se manifesta em sua aparência e de que é preciso buscar a concretude de cada fato, o seu relacionamento com as outras partes que compõem a totalidade do ser social, analisando contradições e possibilidades de superação, ele passa a compreender a necessidade de estranhar seu cotidiano e entendê-lo como categoria analítica, fundamental para conhecer o objeto em seus aspectos gerais e, também, como categoria empírica, capaz de denotar as determinações e especificidades que se expressam na realidade. 
Nesse sentido, além de embasarem decisões profissionais e serem fundamentais para a construção de sua capacidade argumentativa e seus posicionamentos político-interventivos junto a usuários, familiares, profissionais de forma geral e gestores, as investigações construídas ao longo do trabalho do assistente social também podem indicar a necessidade de o profissional aprofundar seus estudos a respeito de aspectos específicos do fenômeno investigado, a fim de descortinar suas determinações, expressões, contradições, consequências e os desafios vinculados ao contexto particular em que se manifesta, caracterizado por aspectos singulares e determinado pela totalidade social.

Assim, se a dimensão investigativa se apresenta como uma primeira tentativa de aproximação crítica para construção de análises críticas, suas problematizações podem indicar a necessidade de aprofundar os estudos referentes às determinadas problemáticas.

Nessa situação, a pesquisa se apresenta como uma estratégia que, ao ser articulada a postura investigativa, pode desvendar questões enigmáticas no trabalho profissional. Nesse processo, efetivar o acesso do usuário a um benefício, ao atendimento médico, a uma passagem para retornar para sua cidade de origem, dentre outros, embora seja importante e caminhe na direção de garantir o que lhe é de direito, não é suficiente. Faz-se necessário refletir e construir estratégias para compreender as semelhanças e diferenças que existem entre esses usuários; o que determina sua busca pelos serviços institucionais para além da finalidade expressa na fala imediata do usuário; as regras que estão por detrás das interações de tais sujeitos, analisando a importância dessas informações para o trabalho profissional.

Essas questões, que devem ser constantes durante o trabalho profissional, denotam real significado ao valor da dimensão investigativa ao longo do fazer do assistente social. No entanto, em muitos momentos, o profissional perceberá que o caráter de horizontalidade e permanência da dimensão investigativa também supõe processualidade e transitoriedade para intervenções, bem como para reflexões mais aprofundadas referentes a aspectos mais específicos da realidade, o que requererá planejar sua abordagem teórica e empírica por meio do trabalho de pesquisa.

Esse planejamento da pesquisa supõe que sua proposta seja sistematizada por meio de um projeto que seja reflexivo e convincente em termos de delimitação do que se quer pesquisar, os motivos para sua realização, as variáveis que se pretende investigar, os objetivos que se intenciona alcançar e a metodologia adotada para se aproximar dos sujeitos, mantendo o respeito e a ética necessária à condução do trabalho. Além disso, é fundamental que o assistente social recorra à bibliografia produzida sobre o assunto na tentativa de lapidar seu olhar e problematizações, ampliando seu horizonte de análise.

Nesse sentido, é insubstituível o cuidado na seleção de bibliografias, seja para acessar aquelas validadas no terreno acadêmico, seja para a compreensão crítica a respeito da perspectiva de análise dos autores, visto que os temas referentes à realidade social, e que têm sido objeto do Serviço Social, também têm sido abordados por diferentes ciências a partir de perspectivas de análises diversas, o que pode ser determinante para o processo de “despolitização ou politização à direita” (IAMAMOTO, 2014) por parte do assistente social.

Por outro lado, o fato de serem temas de interesse de diversas ciências, também pode contribuir para que as propostas de pesquisa edificadas pelo Serviço Social, no interior das instituições sociais de trabalho, sejam desenvolvidas em conjunto com outros profissionais, pautadas em consistência teórica articulada à relevância social. O mesmo também pode ocorrer em trabalhos de pesquisa propostos por outros profissionais.

Mas, ainda que essas pesquisas não sejam desenvolvidas em uma perspectiva interdisciplinar, existem possibilidades de construção de debates referentes a seus resultados e análises, contribuindo para edificação de alianças, no interior das instituições, capazes de questionar o poder existente, articulando a análise crítica a propostas criativas e emancipadoras.

Tudo isso para dizer que, se a dimensão investigativa constitui uma primeira forma de aproximação crítica para a construção de análises críticas, a pesquisa associada ao trabalho profissional avança na aproximação crítica da realidade ao particularizar determinados aspectos da realidade de trabalho e ter a possibilidade de construção de alianças com outros profissionais no desenvolvimento de suas propostas, de se aprofundar os estudos teóricos, direcionar o olhar investigativo durante a construção dessas propostas, debater as variáveis encontradas na pesquisa bibliográfica e de campo, discutir e analisar as diferentes dimensões interpretativas presentes na formação dos profissionais participantes da pesquisa e construir análises capazes de enriquecer teórica e subjetivamente profissionais e usuários, além de poder proporcionar à instituição possibilidades de ações democráticas e pautadas na justiça social. E, embora não deva ser confundida com a pesquisa acadêmico-científica, nessas condições, expressa um nível elevado de problematização de realidade, capaz de alimentar e indicar novos caminhos à pesquisa científica na (re)construção de teorias.

Assim, sinalizou-se a necessidade de "plasmar a pesquisa" (BATTINI, 2009, p. 54) na intervenção profissional do assistente social, compreendendo que ela pode ser fundamental para romper o academicismo e até a unidisciplina no trabalho profissional. 
O indicativo é que o trabalho profissional, no sentido ampliado, tem sido o principal fundamento/base para construção do processo de pesquisa em Serviço Social (acadêmico-científica e em serviços). Assim, o olhar da investigação e a própria sistematização deverão estar presentes em todos os momentos, mesmo naqueles em que não se está propondo um trabalho de pesquisa propriamente dito.

É de fundamental importância tomar o processo de produção de conhecimentos como elemento de transformação da realidade social, reconhecendo o conhecimento como uma das expressões da práxis, como uma das objetivações possíveis do trabalho humano.

No entanto, nota-se que nem sempre aquilo que o profissional tem a intenção de fazer torna-se possível. Portanto, a análise da pesquisa, associada ao trabalho profissional, não pode ser reduzida à exclusiva responsabilização e iniciativa do assistente social, visto que existem determinantes que se relacionam à formação profissional cada vez mais precária e vinculada à perspectiva mercadológica; ao mercado de trabalho, por meio de vínculos temporários, contratos para atividades específicas; às políticas sociais, que têm sofrido novas configurações em que predomina a separação entre seus formuladores e executores; ao autoritarismo; clientelismo; coronelismo; e à corrupção. Além de mudanças cíclicas em curto período de tempo entre gestores de políticas, que implicam compreensões diferenciadas a respeito do Serviço Social, desenhando novas demandas institucionais à categoria.

Todos estes processos supracitados atingem diretamente o trabalho profissional, tentando reduzi-lo aos interesses dominantes, expressos na gestão municipal, estadual ou federal, ou no interior de instituições privadas, ameaçando o profissional de perda do vínculo empregatício no caso de contrato de trabalho, ou de remanejamento para locais distantes e de difícil acesso, em caso de profissionais efetivados por meio de concursos públicos.

Assim, não raras vezes, é possível identificar que o discurso de valorização da pesquisa, presente entre os assistentes sociais, não tem se materializado em seu trabalho profissional. As justificativas por parte dos assistentes sociais são muitas e se referem, sobretudo, aos processos de precarização do trabalho e da formação profissional.

Mesmo com essas restrições, é possível deparar-se com situações em que a pesquisa é incorporada ao trabalho do assistente social, sobretudo por motivo de cursos de especialização. Nesses casos, predomina a compreensão de que pesquisa deve ser realizada na academia e que o trabalho é o lugar da ação (MORAES; JUNCÁ; SANTOS, 2010).

Assim, se por um lado há um discurso de valorização da pesquisa em serviços, por outro, majoritariamente, ela não tem sido associada ao trabalho profissional, seja por questões ligadas à sua situação de trabalho, marcadas fortemente pela precarização, seja por questões vinculadas à formação e à falta do aprimoramento profissional constante ou, ainda, por vincular a pesquisa exclusivamente à academia.

Nesse compasso, associado ao discurso de valorização da pesquisa, o profissional, por vezes, articula pequenos e eventuais levantamentos empíricos realizados sem planejamento, em seu local de trabalho, ao termo pesquisa, construindo um processo de banalização, enfraquecendo o modo como esses dados e análises são produzidos, restringindo-a ao empirismo e desvalorizando suas possíveis contribuições teóricas e éticopolíticas para a intervenção profissional (MORAES, 2016b).

Com tais considerações, reforça-se a nossa concepção de pesquisa em serviços como aquela que se origina de demandas institucionais e/ou de uma preocupação ético-política profissional de garantir a qualidade dos serviços prestados à população, articulando-se, muitas vezes, a atividades acadêmicas (do profissional e/ou de estagiários) e compreendendo que o processo de indagação inacabada - desnaturalização dos fenômenos sociais e compreensão de seus determinantes - não se alicerça exclusivamente na intenção da ação, mas na construção de informações e dados edificados e sistematizados ao longo do trabalho profissional, por meio de postura e ação investigativa indissociadas da dimensão interventiva.

Associada ao prazer da descoberta, à autonomia e à liberdade na construção de conhecimentos instrumentalizadores da intervenção e encarada como um desafio capaz de mobilizar a consciência do próprio profissional, na tentativa do progresso intelectual e social, a pesquisa enobrece a experiência humana de conhecer o mundo e de capturar o teórico, o histórico e o concreto para ações transformadoras. Assim, a pesquisa também é prática política, porque, ao imergir e manter o elo com uma realidade em constante movimento, descortina um leque de possibilidades reflexivas no interior da categoria profissional para construção de estratégias coletivas de superação da situação analisada, além de realimentar novas aproximações e sucessivas reflexões e problematizações.

\section{Considerações finais}

O lugar que a pesquisa tem ocupado na formação em Serviço Social tem apontado que a difícil missão de garantir sua transversalidade, embora seja um discurso presente entre profissionais do Ensino Superior, é 
atacado pelas atuais condições da política de educação superior na era do "neoliberalismo do século XXI" (MORAES, 2016b, p. 63).

Consequência destes processos, a precarização, intensificação do trabalho docente e as alterações em sua rotina de trabalho têm contribuído para o aligeiramento da pesquisa e da construção de conhecimentos de forma crítica e autônoma.

Portanto, embora o Serviço Social, enquanto área produtora de conhecimentos e fundamentado em seu projeto profissional, insista no questionamento e enfrentamento da cultura dominante e do conservadorismo, dialeticamente é afetado pela realidade capitalista e as atuais condições da política de educação superior, que o tem fragilizado e contribuído, em dados momentos, para a construção de investigações tecnicistas através de sistematizações de levantamentos.

Além disso, o Serviço Social, particularmente no contexto da graduação, deve refletir a respeito de outro aspecto fundamental: a centralidade e transversalidade da pesquisa em serviços na formação de futuros assistentes sociais. Ou seja, a defesa da transversalidade da pesquisa em Serviço Social na formação profissional do assistente social, no século XXI, supõe a defesa da centralidade da pesquisa acadêmico-científica e da pesquisa em serviços, ancoradas nos atuais valores ético-políticos profissionais.

Essas questões, pouco valorizadas nos debates profissionais, indicam a necessidade de discutir, além de como garantir a transversalidade da pesquisa (acadêmico-científica e em serviços) na formação profissional, os objetivos delineados em suas propostas, considerando a produção de conhecimentos críticos e também de reflexões a respeito de possibilidades político-interventivas.

\section{Referências}

BARBIANI, R. Sobre o ato de conhecer e o conhecer em ato... onde está o sujeito da frase? In: ENCONTRO NACIONAL DE PESQUISADORES EM SERVIÇO SOCIAL, 9., 2004, Porto Alegre. Anais... [S.l.]: ABEPSS. Não paginado. 1 CD-ROM.

BATTINI, O. Atitude investigativa e prática profissional. In: BAPTISTA, M. V.; BATTINI, O. (Org.). A prática profissional do assistente social: teoria, ação, construção de conhecimento. São Paulo: Veras, 2009. p. 53-78.

BOURGUIGNON, J. A. A particularidade histórica da pesquisa no Serviço Social. São Paulo: Veras; Ponta Grossa: UEPG, 2008.

IAMAMOTO, M. V. Formação profissional na consolidação do projeto ético-político do Serviço Social brasileiro: fundamentos, resistências e desafios conjunturais. In: SEMINÁRIO ANUAL DE SERVIÇO SOCIAL, 7., 2014, São Paulo. VII Seminário... São Paulo: Cortez, 2014. Disponível em: <https://www.youtube.com/watch?v=zDOnXgCH_1Y>. Acesso em: 01 jul. 2014.

KAMEYAMA, N. A trajetória da produção de conhecimentos em Serviço Social: avanços e tendências (1975 a 1997). [1998?]. Disponível em: <http://www.ts.ucr.ac.cr/binarios/congresos/reg/slets/slets-016-088.pdf>. Acesso em: 7 jan. 2015.

MAURIEL, A. P.; GUEDES, O. de S. Desafios da pesquisa na formação profissional do assistente social: um olhar a partir da experiência do curso “ABEPSS-Itinerante”. Temporalis, Brasília/DF, v. 13, n. 25, p. 13-32, jan./jun. 2013.

MENDES, J. M. R.; ALMEIDA, B. de L. F. de. As recentes tendências da pesquisa em Serviço Social. Serviço Social e Sociedade, São Paulo, n. 20, p. 640-661, out./dez. 2014.

MINAYO, M. C. de S. O desafio do conhecimento: pesquisa qualitativa em saúde. 14. ed. São Paulo: Hucitec, 2014.

MORAES, C. A. S. Os desafios do novo século à formação em Serviço Social. Temporalis, Brasília, v. 16, n. 31, p. 105-131, jan./jun. 2016a. Disponível em: <http://periodicos.ufes.br/temporalis/article/view/12226>. Acesso em: 29 jan. 2017.

. O Serviço Social brasileiro na entrada do século XXI: formação, trabalho, pesquisa, dimensão investigativa e a particularidade da saúde. 2016. 318 f. Tese (Doutorado em Serviço Social) - Pontifícia Universidade Católica de São Paulo, São Paulo, 2016b.

.; JUNCÁ, D. C. de M.; SANTOS, K. de S. Para quê, para quem, como? Alguns desafios do cotidiano da pesquisa em serviço social. Serviço Social e Sociedade, São Paulo, n. 103, p. 433-452, jul./set. 2010.

SETÚBAL, A. A. Pesquisa em Serviço Social: utopia e realidade. 5. ed. São Paulo: Cortez, 2011.

SIMIONATTO, I. Intelectualidade, política e produção do conhecimento: desafios ao Serviço Social. Serviço Social e Sociedade, São Paulo, n. 117, p. 7-21, jan./mar. 2014.

VASCONCELOS, A. M. et al. Produção de conhecimento na área de Serviço Social e Projeto Ético Político. Anais do ENPESS (20082010) e CBAS (2007-2010). In: CONGRESSO BRASILEIRO DE ASSISTENTES SOCIAIS, 14., 2013, Águas de Lindóia. Anais... Brasília: CFESS/ABEPSS, 2013. v. 1, p. 1-15.

ZACARIAS, I. R. et al. Programas de Pós-graduação em Serviço Social: tendências nas áreas de concentração, linhas de pesquisa e disciplinas. In: ENCONTRO NACIONAL DE PESQUISADORES EM SERVIÇO SOCIAL, 14., 2014, Natal. Anais... [S.l.]: ABEPSS, 2014. Não paginado. 1 CD-ROM. 


\section{Notas}

1 Este artigo é fruto de tese de doutorado defendida em 2016 no Programa de Estudos de Pós-Graduação em Serviço Social da PUC-SP, sob o título: "O Serviço Social brasileiro na entrada do século XXI: formação, trabalho, pesquisa, dimensão investigativa e a particularidade da saúde” e contribuiu para construção de uma proposta de pesquisa guarda-chuva, financiada pela FAPERJ (2017-2019), intitulada "Mercado de trabalho e espaços sócio-ocupacionais do Serviço Social nas Regiões Norte e Noroeste Fluminense”, especialmente, do subprojeto "Política Social brasileira e mercado de trabalho para assistentes sociais nas Regiões Norte e Noroeste Fluminense" coordenado por este subescritor.

2 Embora as análises da política de educação superior atual indiquem a perda de centralidade da pesquisa e da produção de conhecimentos em articulação com o ensino e extensão, concentrando-se em universidades de ponta.

\section{Carlos Antonio de Souza Moraes}

as.carlosmoraes@gmail.com

Doutorado em Serviço Social pela Pontifícia Universidade Católica de São Paulo (PUC-SP)

Professor Adjunto do Departamento de Serviço Social de Campos da Universidade Federal Fluminense (UFF) Líder do Grupo Interdisciplinar de Estudo e Pesquisa em Cotidiano e Saúde (GRIPES)

\section{UFF}

Rua José do Patrocínio, 71

Sala 109 - GRIPES

Campos dos Goytacazes - Rio de Janeiro - Brasil

CEP: 28.010 -385 